Int. J. Dev. Biol. 53: 559-568 (2009)

doi: $10.1387 / \mathrm{ijdb} .082777$ na

\title{
EphrinA-EphA receptor interactions in mouse spinal neurulation: implications for neural fold fusion
}

\author{
NORAISHAH M. ABDUL-AZIZ1,\# MARK TURMAINE², NICHOLAS D.E. GREENE ${ }^{1}$ and ANDREW J. COPP*,1 \\ ${ }^{1}$ Neural Development Unit, UCL Institute of Child Health and ${ }^{2}$ UCL Division of Biosciences, London, UK
}

\begin{abstract}
The molecular basis of neural fold adhesion and fusion is a poorly understood aspect of neurulation. Cell surface glycosyl phosphatidylinositol (GPI)-anchored proteins have been implicated in neural fold adhesion, with ephrinAs particularly attractive candidates in view of the cranial neural tube defects observed in mice lacking ephrinA5 or the EphA7 receptor. Here, we demonstrate that ephrins $A 1, A 3$ and $A 4$, as well as several EphA receptors, are expressed in the closing mouse spinal neural tube. Most ephrinAs and EphA receptors were found to be expressed in multiple tissues in the caudal region, whereas EphA2 receptor was expressed specifically at the apices of the neural folds just prior to onset of neural tube fusion. Using mouse whole embryo culture, we found that cleavage of GPI-anchored molecules from the embryonic cell surface resulted in delay of spinal neural tube closure. Injection of EphA1 and EphA3 fusion proteins intraamniotically into cultured embryos was used to specifically disrupt ephrinA-EphA receptor interactions, and led to inhibition of spinal neural tube closure, without adverse effects on growth or developmental progression. These treatments did not disturb neural plate bending or neural fold elevation, both of which are critical for spinal neural tube closure. Our findings demonstrate that ephrinA-EphA receptor interactions are required for closure of the mouse spinal neural tube, and support the hypothesis that ephrinA-EphA receptor interactions may participate in the molecular recognition events that culminate in adhesion and fusion of the tips of the neural folds during spinal neurulation.
\end{abstract}

KEY WORDS: morphogenesis, neural tube, embryo culture, adhesion, GPI anchor

\section{Introduction}

Neurulation, the formation of the neural tube, is a fundamental early component in the establishment of the vertebrate central nervous system. Many studies have examined the cellular and molecular processes that underlie the initial shaping of the neural plate, and its bending during elevation of the neural folds (Colas and Schoenwolf, 2001; Schoenwolf and Smith, 1990; Copp et al., 2003). Much less attention has been paid to the subsequent event of midline neural fold fusion, which occurs progressively along the entire axis of the neurulating embryo, and which marks the completion of neural tube closure.

In amphibians, birds and mammals, a zone of altered cell morphology with numerous rounded cellular blebs has been observed along the tips of the neural folds, immediately prior to fusion. These surface alterations are suggested to reflect the cellular events that enable adhesion between the folds (Waterman, 1975; Waterman, 1976; Rice and Moran, 1977; Lawson and England, 1998). Moreover, lamellipodial and filopodial cellular protrusions have been observed emerging from the tips of the neural folds and linking with each other across the midline (Geelen and Langman, 1979). Similar observations have been made in other morphogenetic systems, for example the closing palatal shelves and fusing eyelids, in which membrane specialisations are observed at the sites of incipient adhesion and

\footnotetext{
Abbreviations used in this paper: AP, alkaline phosphatase; Eph, ephrin receptor; FBS, fetal bovine serum; GPI, glycosyl phosphatidylinositol; HBSS, Hank's balanced salt solution; PBS, phosphate buffered saline; PIPLC, phosphatidylinositol-specific phospholipase C; PNP, posterior neuropore; RAP, receptor affinity probe; RT-PCR, reverse transcriptase polymerase chain reaction.
}

*Address correspondence to: Prof. Andrew Copp. Neural Development Unit, UCL Institute of Child Health, London WC1N 1EH, UK. e-mail: a.copp@ich.ucl.ac.uk - Lab web-page: http://www.ich.ucl.ac.uk/ich/academicunits/Neural_development/Homepage

\#Current address: Department of Parasitology, Faculty of Medicine, University of Malaya, 50603 Kuala Lumpur, Malaysia 
fusion (Gato et al., 2002; Tao et al., 2005).

Molecular clues to the events of neural fold adhesion and fusion have come from studies in which the apposing tips of the neural folds were found to be covered with extracellular carbohydrate-rich material which stains with ruthenium red (Sadler, 1978) and contains alpha-D-mannose, alpha-D-glucose and $\mathrm{N}$-acetylD-glucosamine sugar residues (Smits van Prooije et al., 1986). Removal of this extracellular material using phospholipase $\mathrm{C}$ in whole embryo culture resulted in neural tube closure defects (O'Shea and Kaufman, 1980). Since cell surface glycosyl phosphatidyl-inositol (GPI) linkages are amongst the targets of phospholipase C (Andrews et al., 1988), this finding raises the possibility that GPI-anchored molecules may participate in neural fold fusion.

Independent evidence implicating GPI-anchored molecules in neural fold fusion has come from the finding of cranial neural fold fusion defects in mice lacking ephrinA5 or EphA7 (Holmberg et al., 2000). EphrinA5, like other members of the ephrinA family, is a GPI-anchored cell surface ligand that interacts with members of the transmembrane EphA receptor family. Although best known for their repulsive effects, for example in retinal axon guidance (Drescher, 1997), ephrinA-EphA interactions can also be attractive in some cellular contexts, as was suggested for the putative role in cranial neural tube closure (Holmberg et al., 2000).

Despite the evidence implicating ephrinA-EphA interactions in cranial neural fold adhesion and fusion, it is notable that defects of spinal neurulation were not observed in the ephrinA5 and EphA7 knockouts (Holmberg et al., 2000). Indeed, to date there has been no systematic study of either the expression or function of the ephrinA-EphA system during spinal neural tube closure. In the present study, we show that several ephrinAs and EphA receptors are expressed during mouse spinal neurulation. By treating cultured embryos with phosphatidylinositol-specific phospholipase $\mathrm{C}$, we confirm that GPI-anchored molecules are required for spinal neural tube closure. Moreover, by applying exogenous EphA fusion proteins to neurulation stage embryos in culture, we demonstrate a requirement for binding between ephrinAs and endogenous EphA receptors in neurulation. This study provides the first evidence for a role of ephrinA-EphA interactions in closure of the mouse spinal neural tube.

\section{Results}

\section{Ephrin $\mathrm{A} 1$ and $\mathrm{A} 3$ are expressed during mouse spinal neuru- lation}

To gain insight into the ephrinAs that might participate in mouse spinal neurulation, we studied the distribution of their mRNAs by whole mount in situ hybridisation. At E8.5, both ephrin $A 1$ and $A 3$ are strongly expressed in the caudal region (Figure $1 A, G$ ), including the region of open neural folds, termed the posterior neuropore (PNP). In sections, ephrinA1 transcripts are detected in the open neural plate of the PNP but with reducing intensity rostrally, towards the site of neural fold fusion (Figure 2AD). In contrast, ephrinA 3 is expressed more uniformly throughout the E8.5 PNP (Figure 2E-H), although with most intense expression in paraxial mesoderm. By E9.5, ephrinA1 transcripts become confined to the ventral tissues of the PNP and tail bud (Figure 1B,C; Figure 2I-L), whereas ephrinA3 expression extends more rostrally into the trunk region (Figure $1 \mathrm{H}, \mathrm{I})$. In the PNP region,
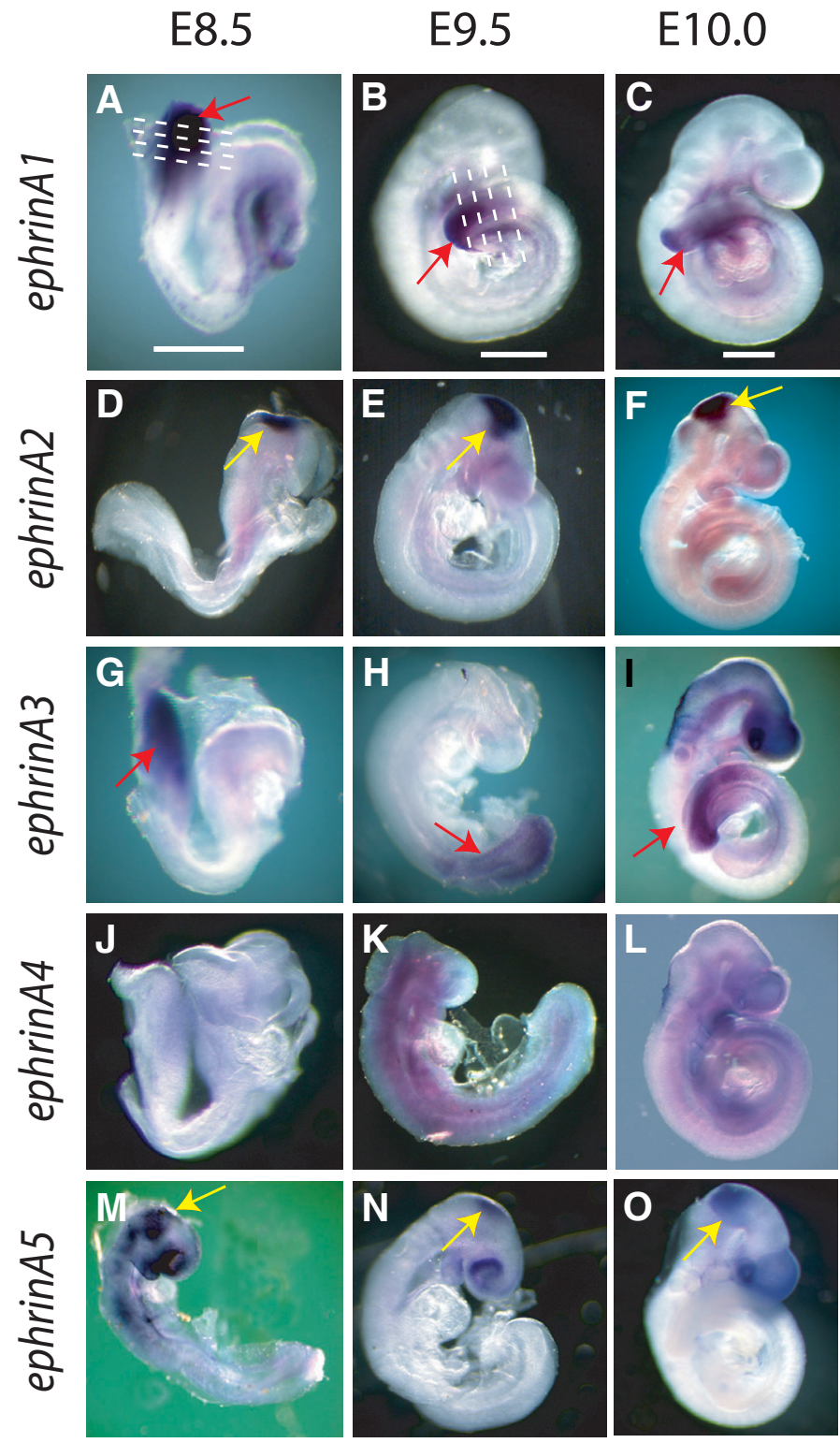

Fig. 1. Expression of ephrinAs during mouse neurulation. Whole mount in situ hybridisation of embryos at $E 8.5(6-8$ somites $)(\mathbf{A}, \mathbf{D}, \mathbf{G}, \mathbf{J}, \mathbf{M})$, E9.5 (12-17 somites) (B,E,H,K,N) and E10 (25-26 somites) (C, $\mathbf{F}, \mathbf{I}, \mathbf{L}, \mathbf{O})$. EphrinA1 and ephrinA3 transcripts are localised to the posterior neuropore (PNP) region (red arrows in A-C and G-I), with ephrinA1 additionally expressed in the branchial arches. EphrinA2 and ephrinA5 mRNAs are localized to the midbrain (yellow arrows in D-F and M-O), with ephrinA5 additionally expressed in the optic vesicle and telencephalon. EphrinA4 is expressed ubiquitously, with an increase in intensity at E9.5 (J-L). Dashed lines $(A, B)$ indicate plane of sections in Fig. 2. Scale bars, $0.5 \mathrm{~mm}$.

ephrinA 3 is expressed most strongly in the lateral paraxial mesoderm, with low intensity expression also in the neural plate (Figure 2M-P). Expression of ephrinA1 was also detected in the branchial arches at both E8.5 and E9.5 (Figure 1A,B), whereas ephrinA3 becomes expressed in the brain by E10 (Figure 11).

EphrinA2 and $A 5$ are both strongly expressed in a broad cranial domain at E8.5 (Figure 1D,M), with expression gradually becoming localized to the midbrain as neurulation progresses through 
E9.5 to E10 (Figure 1E,F,N,O). In addition, ephrinA5 is expressed in the developing telencephalon (Figure 1O). There is no expression of either of these ephrins in the PNP region. Expression of ephrinA4 is ubiquitous throughout neurulation. E8.5 embryos exhibit low intensity expression (Figure $1 \mathrm{~J}$ ) but by E9.5 ephrinA4 has been up-regulated and this more intense expression continues at E10 (Figure $1 \mathrm{~K}, \mathrm{~L})$.

Hence, several ephrinAs are expressed in the PNP during neurulation, consistent with a role for these GPI-anchored molecules in spinal neural tube closure.

\section{Multiple ephrin receptors are expressed in the spinal neural tube during neurulation}

To survey the expression of ephrin receptors (Ephs) during mouse neurulation, RT-PCR was initially performed on cranial and caudal portions of E8.5 and E9.5 embryos (Figure 3). This showed that, of the EphA receptors studied, all are expressed in the cranial region during this developmental period. In the caudal region, EphA1, A2, $A 4$ and $A 5$ are expressed strongly, while EphA3 and $A 8$ are also detectable. Expression of EphA7 is not observed.

Whole mount in situ hybridisation, together with analysis of transverse sections, was used to document the distribution of EphA1, A2, A4 and A5 transcripts in the E9.5 caudal region. EphA1 has a rather general expression pattern, being expressed throughout the neuroepithelium, paraxial mesoderm, notochord and dorsal hindgut (Figure 4A-D), although not in ventral tissues. EphA5 is expressed particularly in the PNP region (Figure 4M) and sections reveal that transcripts are present strongly throughout the neuroepithelium and at low level in other tissues (Figure $4 \mathrm{~N}-\mathrm{P})$.

In contrast, EphA2 and EphA4 exhibit tissue-specific expression. EphA2 is expressed strongly in the neuroepithelium and notochord, but not in the paraxial mesoderm and hindgut, with a striking variation in expression pattern along the spinal axis (Figure 4E-H). In the open PNP, EphA2 transcripts are present throughout the neuroepithelium but more rostrally, towards the site of neural fold adhesion and fusion, EphA2 expression becomes highly restricted with transcripts detected only in the apposing tips of the neural folds (Figure $4 \mathrm{H}, \mathrm{Q}$ ). This very specific pattern of EphA2 expression was reproducible in multiple embryos at this stage (Figure $4 \mathrm{Q}$, insets). The expression pattern of EphA4 is almost complementary to EphA2, with strong expression in the paraxial mesoderm and only low intensity, patchy expression in the neural plate (Figure 4I-L). Nevertheless, there appears to be enhanced expression of EphA4 at the neural fold tips when adhesion and fusion are underway (Figure 4L).

Hence, while several EphA receptors are expressed in the closing spinal neural folds, the specific localisation of EphA2 and EphA4 transcripts is particularly suggestive of a role in neural fold adhesion and fusion. To examine the localization of EphA2 expression in greater detail, we performed immunoelectron microscopy on E9.5 embryos. This analysis confirmed that EphA2 is present at the tips of the neural folds and suggests, moreover, that it is expressed mainly in the surface ectoderm, which forms the leading edge of the neural fold at the
Fig. 2. Expression of ephrinAs in the mouse posterior neuropore (PNP). Transverse sections through the PNP region of E8.5 (AH) and E9.5 (I-P) embryos hybridized as whole mounts (indicated by dashed lines in Fig. $1 A, B)$ for expression of ephrinA1 (A-D, I-L) and ephrinA3 (E-H, M-P). Successive sections are in caudal to rostral sequence, left to right. EphrinA1 is expressed in the caudal-most neural plate at E8.5, whereas expression becomes downregulated more rostrally, near the point of neural fold adhesion and fusion (A-D). Ventrally, expression is intense in the mid/hindgut. At E9.5 (I-L), ephrinA1 is expressed ventrally in lateral plate mesoderm and hindgut, whereas transcripts are absent from the neural plate.

EphrinA3 transcripts are present at E8.5 (E-H) and E9.5 (M-P) particularly in the lateral paraxial mesoderm and, less intensely, in the neural plate. Intensity of expression does not vary along the PNP axis. Abbreviations: hg, hindgut; mes, paraxial mesoderm; np, neural plate. Scale bar: 0.2 mm.

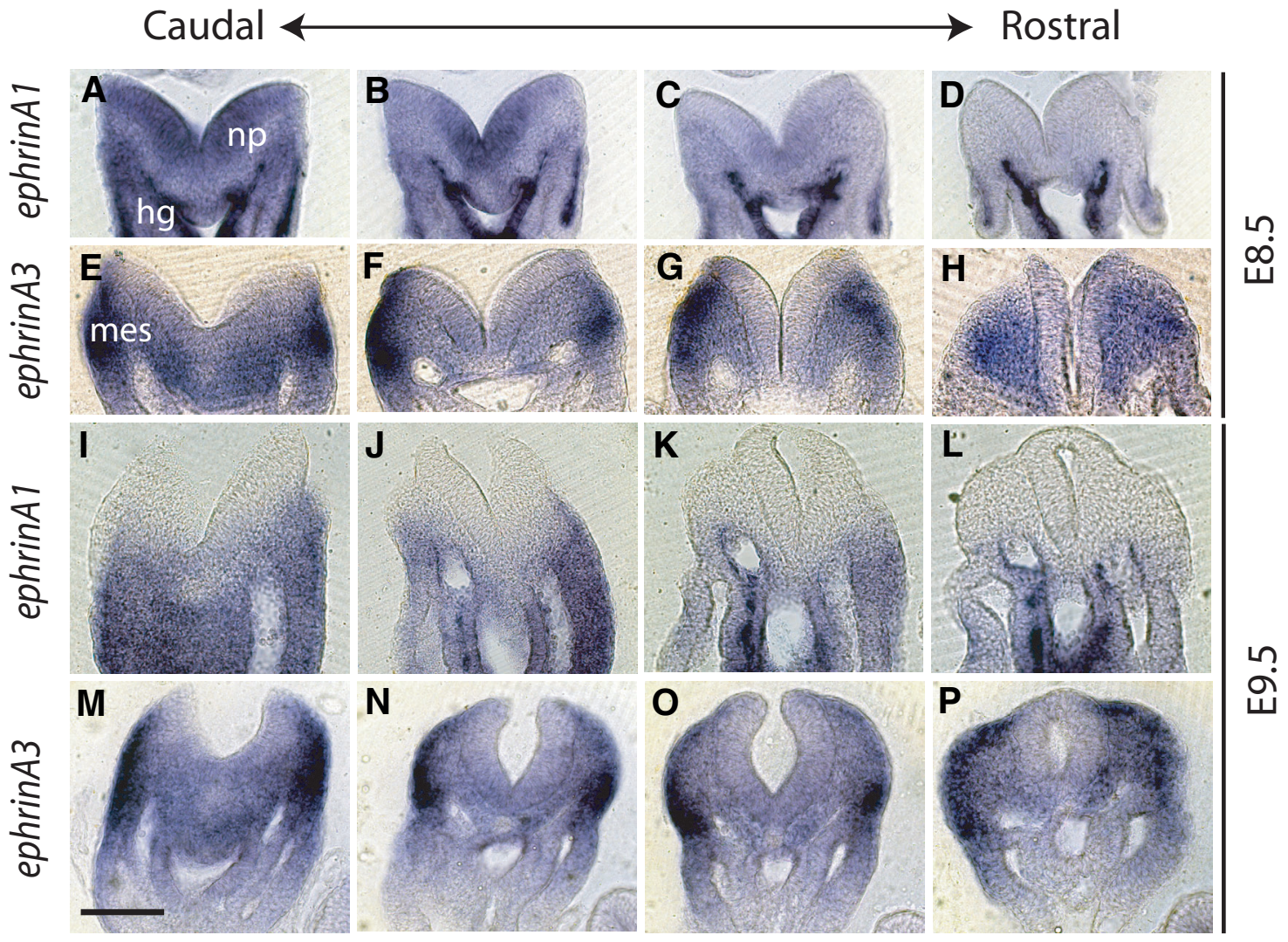

? 


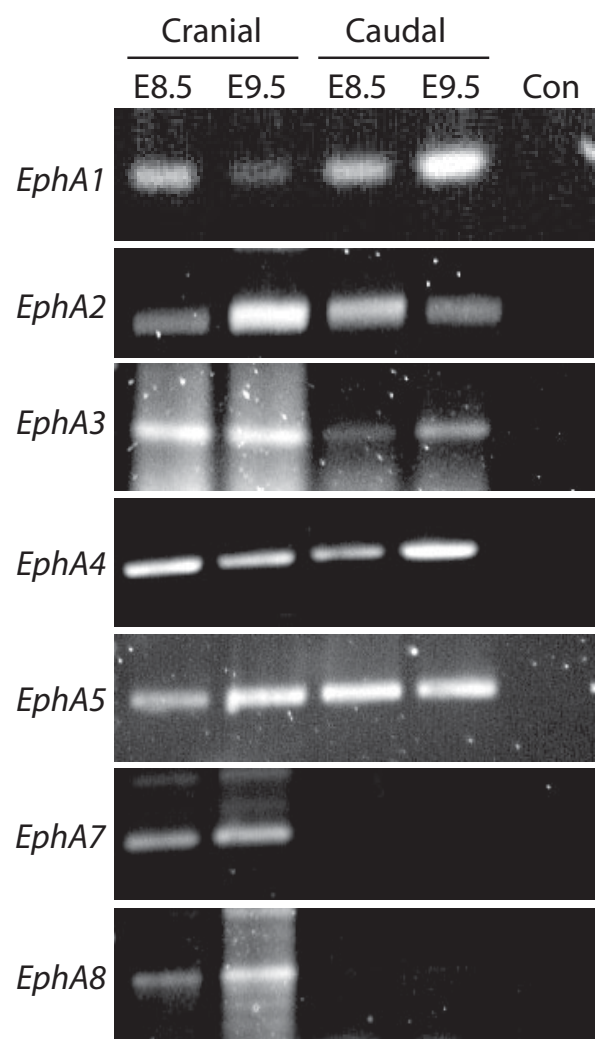

Fig. 3 (Left). RT-PCR detects expression of EphA1, A2, $A 3, A 4, A 5, A 7$ and $A 8$, in E8.5 and/or E9.5 embryos. Cranial and caudal (PNP) regions were prepared, respectively, by transection of the embryo just rostral to the first branchial arch or just caudal to the most recently formed somite. Whereas mRNA for EphA1-A5 is present in both cranial and caudal regions, EphA7 and A8 are detected predominantly in the cranial region. Con: CDNA-free negative control for PCR amplification. The size of the RTPCR products are: EphA1, 495 bp; EphA2, 389 bp; EphA3, 384 bp; EphA4, 557 bp; EphA5, 708 bp; EphA7, 459 bp; EphA8, 392 bp.
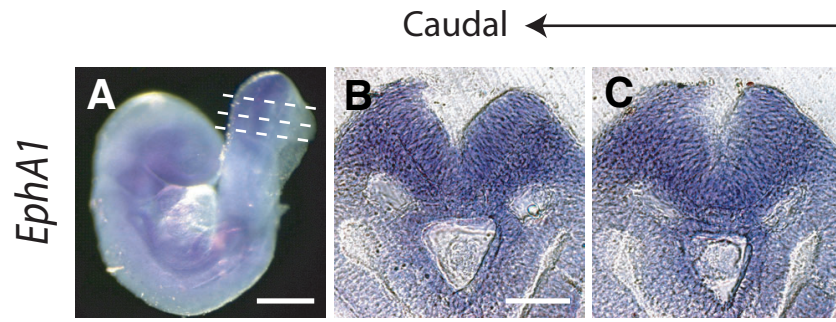

Rostral
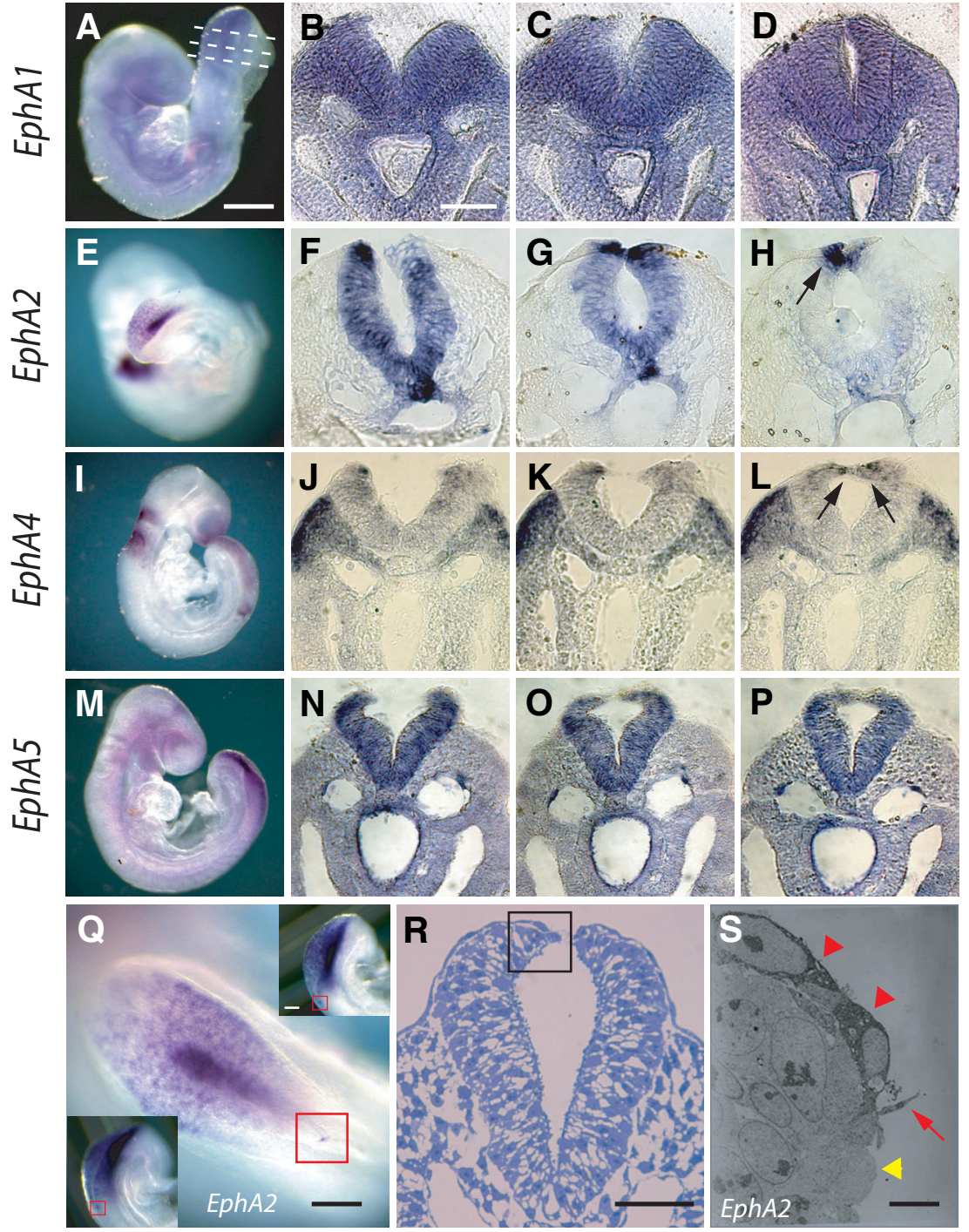

Fig. 4 (Right). Expression of EphA receptors during mouse neurulation. (A-P) Whole mount in situ hybridisation expression analysis of EphA1, $\mathrm{A} 2, \mathrm{~A} 4$ and $\mathrm{A} 5$ in whole E9.5 embryos $(\mathbf{A}, \mathbf{E}, \mathbf{I}, \mathbf{M})$ and vibratome sections through the posterior neuropore (PNP, plane of section as in A) shown in caudal to rostral sequence, left to right (B-D, F-H, J-L, N-P). EphA1 is expressed throughout the neural plate, presomitic mesoderm, notochord and hindgut endoderm (A-D); EphA2 is expressed throughout the neural plate and notochord (E-H), except at the site of neural fold fusion, where expression is solely at the neural fold tips (arrow in H). EphA4 is expressed strongly in the presomitic mesoderm and weakly in the neural plate, with strongest expression in the dorsal neural folds (I-L) particularly at the site of neural fold fusion (arrows in L). Note expression in rhombomeres 3 and 5 . EphA5 is expressed uniformly throughout the neural plate with lower intensity expression in other tissues (M-P). (Q) Dorsal view of PNP region of whole mount hybridisation for EphA2 mRNA, as in (E). Note expression throughout neural plate, with focal site of hybridisation at the point of neural fold fusion (boxed), corresponding to the localized signal in (H). Insets in (Q) show two further embryos, each with a focal site of EphA2 expression at the point of neural fold fusion (boxed). (R,S) Immuno-electron microscopy of EphA2 expression at the neural fold tip (S). Toluidine blue-stained plastic section (R) shows location of thin section in (S) (boxed). Note EphA2 signal in the surface ectoderm cells (red arrowheads), and in a lamellipodiumlike protrusion which extends towards the opposite neural fold (red arrow). Neuroepithelial cells immediately adjacent to the surface ectoderm do not express EphA2 (yellow arrowhead). Scale bars, $0.5 \mathrm{~mm}$ in $A$ (also $E, I, M) ; 0.2 \mathrm{~mm}$ in $B$ (also $C, D, F-H, J-L, N-P$ ); $0.1 \mathrm{~mm}$ in $Q, R ; 9 \mu \mathrm{m}$ in $S$.

site of closure, rather than in adjacent neuroepithelial cells (Figure 4R,S).

\section{GPI-anchored cell surface molecules are required for neural tube closure}

To determine whether GPI-anchored ephrinAs and their EphA receptors play a functional role in neural tube closure, we reinvestigated earlier findings that cleavage of GPI-anchored molecules from neurulation-stage mouse embryos cause neural tube closure defects in culture (O'Shea and Kaufman, 1980). The previous study used non-specific phospholipase $\mathrm{C}$, but we increased the specificity of the treatment by using 
phosphatidylinositol-specific phospholipase C (PIPLC), which cleaves the majority of phosphatidylinositol anchored molecules from the cell surface (Low et al., 1988; Hornberger et al., 1999). As a control, we probed for surface ephrinAs using an EphA3-AP affinity probe and confirmed that PIPLC does indeed cleave GPIanchored proteins, including ephrinAs, from the neuroepithelial surface of cultured embryos (Figure $5 A, B$ ).

E8.5 embryos (6-8 somite stage) were injected intra-amniotically (Figure 6A,B) with varying concentrations of PIPLC, followed by culture for $8 \mathrm{~h}$. PNP length was then determined as a measure of the normality of spinal neurulation. An enlarged PNP at E9.5E10.5 strongly correlates with subsequent development of open spina bifida (Copp, 1985). Embryos that were injected with $5 \mathrm{mU}$ and $10 \mathrm{mU}$ PIPLC exhibited markedly enlarged PNPs, compared with PBS-injected controls (Figure 6C-F and data not shown). Both PNP length (Figure 7A) and width (data not shown) were significantly enlarged in embryos exposed to 5 or $10 \mathrm{mU}$ PIPLC compared with controls. On the other hand, PIPLC had no effect on PNP length or width at lower concentrations.

A question arises about the specificity of this action of PIPLC, since retardation of PNP closure was observed at concentrations where the enzyme first became limiting for developmental progression and growth. Hence, crown-rump length (but not somite number) was significantly reduced in embryos exposed to $5 \mathrm{mU}$ PIPLC, while both crown-rump length and somite number were adversely affected at $10 \mathrm{mU}$ PIPLC (Figure 7B,C). Moreover, blisters on cranial neural folds and a wavy closed neural tube were observed in some embryos, indicating non-specific toxicity of PIPLC (Figure 6E). As an alternative approach, therefore, we next employed a more specific intervention in ephrinA-EphA function during mouse spinal neurulation.

\section{Perturbation of ephrinA-EphA interaction inhibits spinal neu- ral tube closure, without altering the pattern of neural plate bending}

In order to investigate a possible role for GPI-anchored ephrins in PNP closure, exogenous EphA1 or EphA3, fused to the immunoglobulin Fc domain or alkaline phosphatase (AP) respectively, were injected into the amniotic cavity of E8.5 embryos. Exogenous EphA fusion proteins have been shown to block the binding of ephrinAs to their endogenous EphA receptors (Ciossek et al., 1998; Coulthard et al., 2001). After $8 \mathrm{~h}$ culture, embryos treated with either EphA3-AP or EphA1-Fc exhibited a significantly greater PNP length and width compared with control embryos that received the same concentration of Fc or AP alone (Figures 6G-J; $7 D, E)$. Importantly, with this intervention there was no effect on crown-rump length or somite number of the cultured embryos (Figure 7F,G), arguing for a specific effect of the EphA fusion proteins on PNP closure, rather than a general retarding effect on development. These findings demonstrate a requirement for ephrinA-EphA interactions in closure of the spinal neural tube in mouse embryos.

We found that EphA2 is expressed specifically at the apices of the neural folds just prior to and during neural fold fusion in the spinal region. Taken together with the results of the EphA fusion protein perturbation experiments, this might indicate a functional role for ephrinA-EphA interactions in the process of neural fold adhesion and fusion. Alternatively, ephrinA-EphA interactions could be required for another aspect of neurulation. For example,
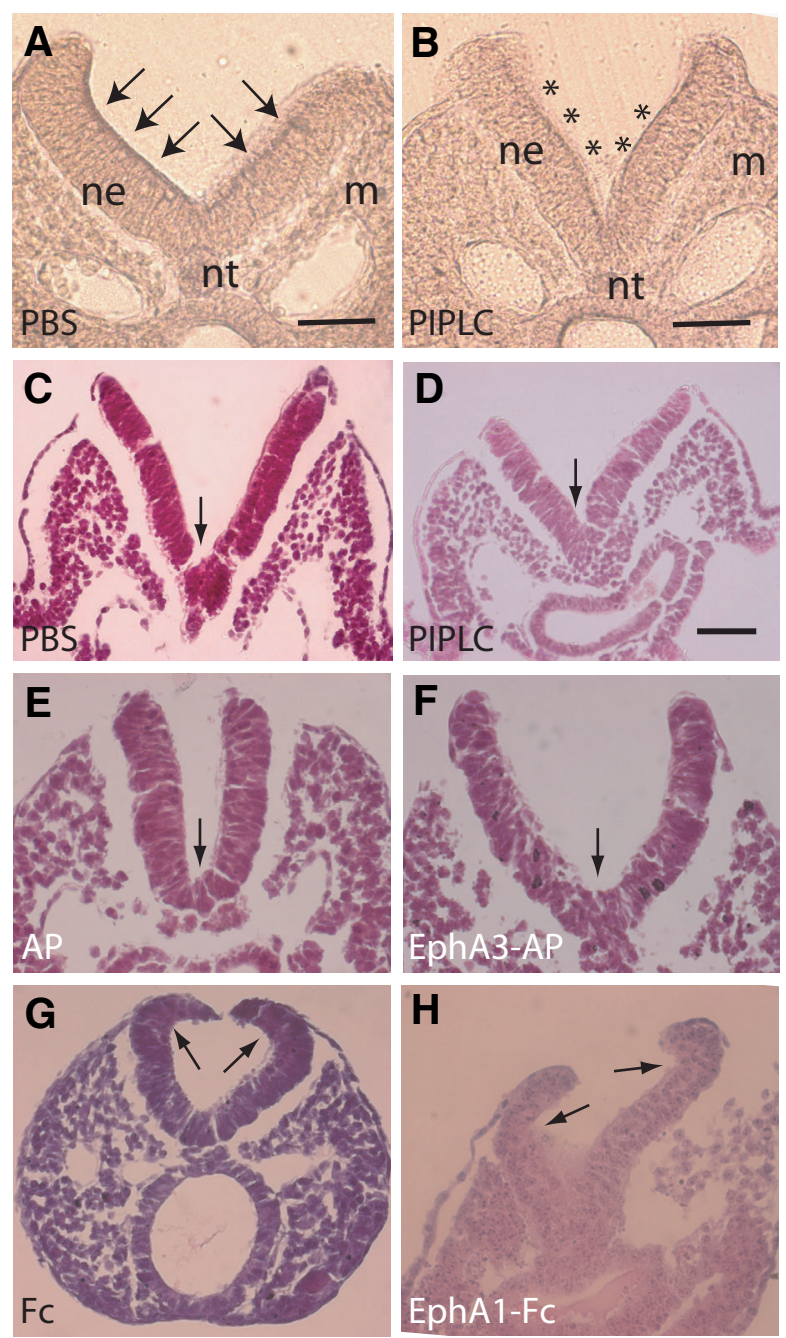

Fig. 5. Phosphatidylinositol-specific phospholipase C (PIPLC) treatment removes cell surface ephrinAs, whereas pattern of neural plate bending is not disturbed by PIPLC or EphA fusion proteins. $(\mathbf{A}, \mathbf{B})$ Receptor affinity probe assay using EphA3-AP to determine the effect of PIPLC treatment on surface ephrinAs in the open PNP region. Enhanced signal is observed on the apical surface of neuroepithelial cells in the PBS-treated control embryo (arrows in (A)) whereas this surface signal is reduced after treatment with $5 \mathrm{mU}$ PIPLC (asterisks in (B)). Nonsurface staining (comparable in $A, B$ ) represents background in this assay since the EphA3-AP probe does not penetrate. Hence, PIPLC cleaves off ephrinAs, and presumably other GPl-anchored proteins, from cultured embryos. Abbreviations: m, paraxial mesoderm; ne, neuroepithelium; nt, notochord. (C-F) E8. 5 embryos exposed in vitro to PBS (C), $5 \mathrm{mU}$ PIPLC (D), $A P(\mathbf{E})$ or EphA3-AP (F) all exhibit normal bending of the neural plate at the median hinge point (arrows). Note the widely open neural folds in the EphA3-AP treated embryo (F). (G,H) Slightly more advanced embryos, at E9.0, exhibit normal dorsolateral hinge point formation (arrows) after exposure to either $F_{C}(\mathbf{G})$ or EphA1- $F_{C}(\mathbf{H})$. Scale bars, $0.05 \mathrm{~mm}$ in $A, B ; 0.1 \mathrm{~mm}$ in $D$ (also C, E-H).

neural fold bending, which is required for elevation and apposition of the neural folds, might be inhibited in the absence of ephrinAEphA interactions. To test this idea, we prepared transverse sections through the PNP region of embryos treated in vitro with PIPLC, EphA3-AP or EphA1-Fc, and their respective controls. 
A
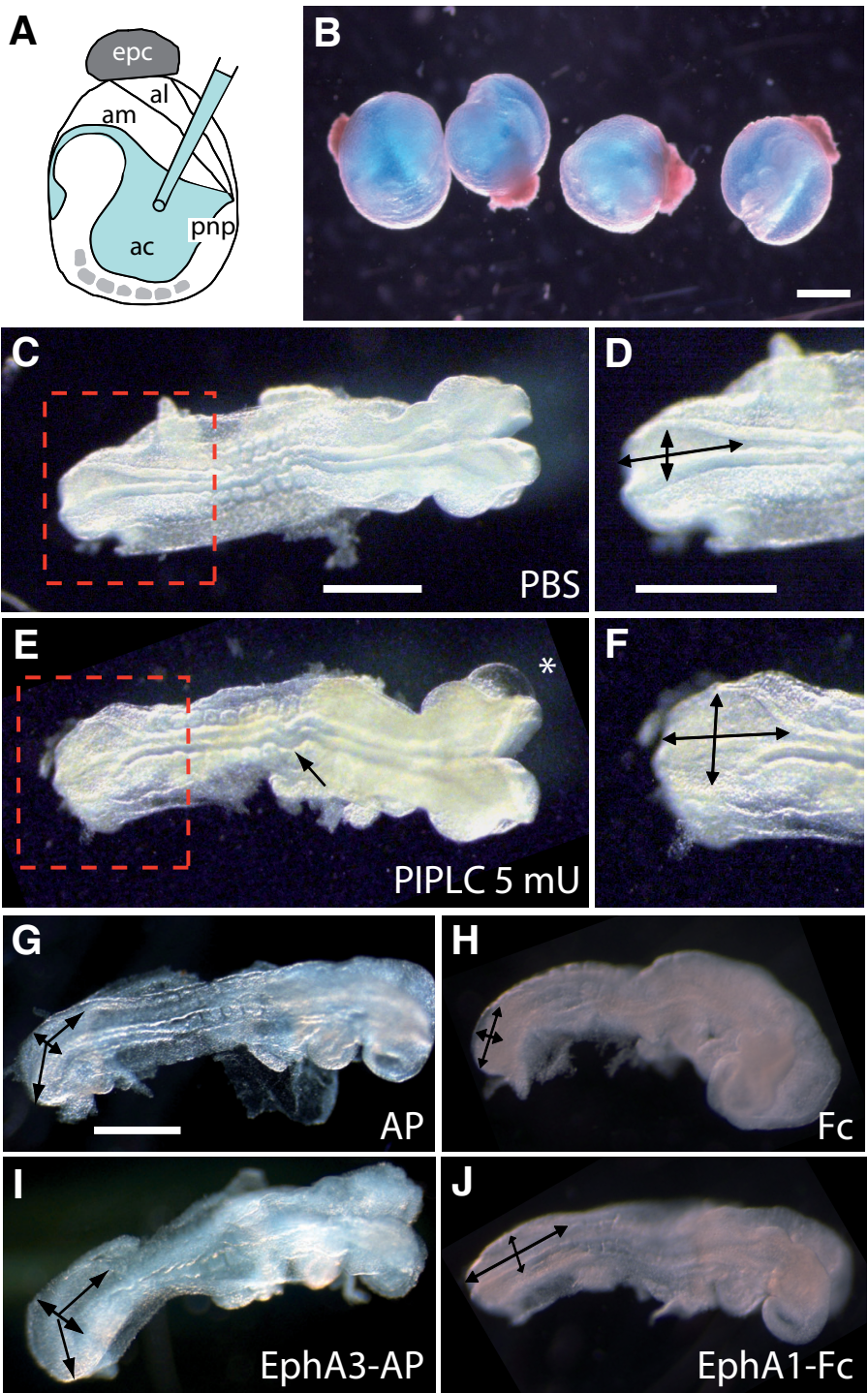

E8.5 embryos exposed to $5 \mathrm{mU}$ PIPLC (Figure 5D) or EphA3-AP (Figure 5F) show apparently normal bending of the neural plate at the median hinge point, compared with PBS- or AP-treated controls (Figure 5C,E). More advanced embryos, at E9.0, treated with EphA1-Fc exhibit normal dorsolateral hinge points (Figure $5 \mathrm{H}$ ), which are characteristic of the PNP at this later stage, compared with Fc-treated controls (Figure 5G). Hence, neural fold morphogenesis is not overtly disturbed by treatments that cause delay in PNP closure, further implicating the process of neural fold adhesion as a step in neurulation that possibly requires EphA-ephrinA interactions.

\section{Discussion}

Ephs and ephrins have been implicated in epithelial adhesion and fusion events in several developmental systems. In mice, cloacal fusion (Dravis et al., 2004), skull suture fusion (Merrill et al., 2006) and atrioventricular valve and septal fusion (Stephen et al., 2007) have all been shown to involve ephrin-Eph interactions. Similar functions are apparent in other species such as
Fig. 6. Removal of glycosyl phosphatidylinositol (GPI)-anchored molecules, or blocking of cell surface ephrinA function, disturbs spinal neurulation. $(\boldsymbol{A}, \boldsymbol{B})$ Method of delivery of PIPLC and EphA fusion proteins to cultured embryos. Diagram demonstrating intra-amniotic injection (A) and whole E8.5 embryos with intact yolk sac and amnion, pre-culture, immediately following intra-amniotic injections of PIPLC plus Fast Green (B). (C-J) Embryos, with extraembryonic membranes removed, at end of $8 \mathrm{~h}$ culture period. Magnified images of $P N P$ region (red boxes) in (C,E) are shown in (D,F) respectively. PNP length and width are indicated by arrows. Embryo injected with PBS/Fast Green demonstrates normal sized PNP (C,D) whereas embryo injected with $5 \mathrm{mU}$ PIPLC/Fast Green exhibits enlarged PNP in both length and width dimensions (E,F). The wavy neural tube (arrow in E) and surface blister on left cranial neural fold (asterisk in E), both indicate mild toxicity of PIPLC treatment. In contrast, embryos injected with EphA3-AP (I) and EphA1-FC (J) fusion proteins do not differ in morphology from their AP (G) and $F_{C}(\mathbf{H})$ controls, apart from a longer and wider PNP. Abbreviations: ac, amniotic cavity; al, allantois; am, amnion; epc, ectoplacental cone; pnp, posterior neuropore. Scale bars, $1 \mathrm{~mm}$ in $B ; 0.5 \mathrm{~mm}$ in C lalso E), D (also F), G (also $\mathrm{H}$-J).

Caenorhabditis elegans where ventral closure depends on function of an Eph tyrosine kinase (George et al., 1998). The finding of midbrain neural tube closure defects in mice lacking ephrinA5 or EphA7 function (Holmberg et al., 2000) points to a further role of ephrin-Eph interactions during morphogenesis, and the results of the present study provide support for this suggestion. Not only are ephrinAs and EphA receptors expressed during the critical stages of spinal neurulation in the mouse embryo, but also perturbation of interactions in the ephrinA-EphA system leads to specific disturbance of neural tube closure. The localization of EphA2 transcripts at the tips of the neural folds is particularly suggestive that the ephrinA-EphA system may function in adhesion and fusion of the neural folds, during the final stage of neurulation. Since EphA2 can bind any of the ephrinA ligands (Pasquale, 2005), it remains unclear which precise ephrinAEphA2 interactions might be functional in mouse neurulation.

\section{How may ephrinA-EphA interactions mediate neural fold ad-} hesion and fusion?

Ephs are integral membrane proteins whereas ephrinAs are linked to the plasma membrane via a GPI anchor. Ephs and ephrins expressed on different cells can 'trans-interact' (Davis et al., 1994; Pasquale, 2005) and it seems possible that neural tube closure requires two-way interactions of this type. Ephs and ephrins on one neural fold might interact with ephrins and Ephs on the opposing fold. If this is confirmed, neural fold adhesion would differ from tissues such as the optic tectum, in which Ephs and ephrins are reciprocally compartmentalized (Drescher, 1997). If trans-interaction is indeed the mode of functioning of the ephrinA-EphA system in neural tube fusion, the question then arises whether ephrinAEphA interactions serve a purely adhesive function, drawing the neural fold tips together and enabling physical union across the midline, or whether there is also a role for down-stream signaling within the cells of the neural fold tips. EphrinAs interact with EphA receptors in a highly promiscuous manner (Gale et al., 1996; Flenniken et al., 1996), giving rise to bidirectional signalling. Events downstream of the EphA receptor tyrosine kinase are designated 'forward' signalling, while events downstream of the GPI-anchored ephrinA ligand are termed 'reverse' signalling. Since ephrinAs do 

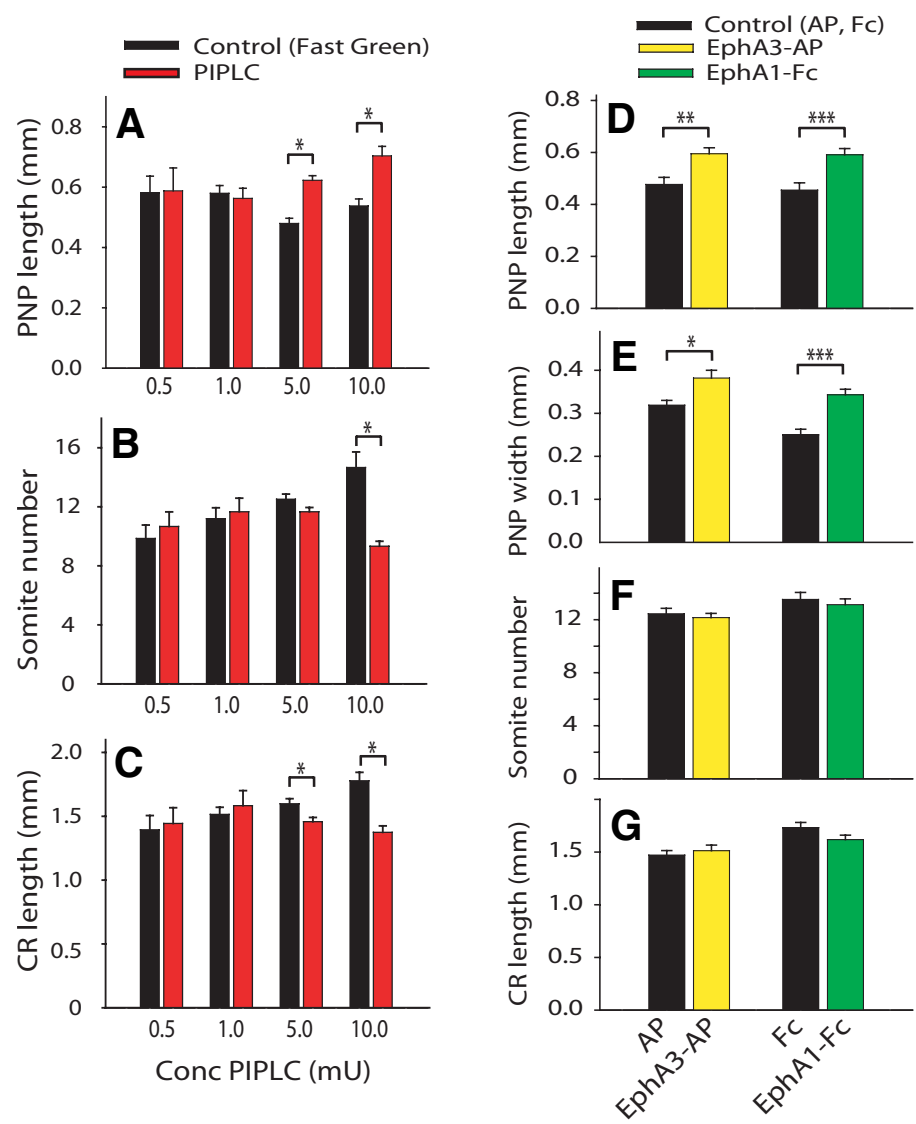

Fig. 7. Effect of phosphatidylinositol-specific phospholipase C (PIPLC) and EphA fusion proteins on posterior neuropore (PNP) closure, embryonic development and growth. (A-C) Dose-response analysis of PIPLC treatment effects on PNP length $(\mathbf{A})$, somite number $(\mathbf{B})$ and crown-rump length (C). Compared with Fast Green (FG)-treated control embryos, PNP length is significantly increased in embryos exposed to PIPLC (ANOVA; $p=0.008$ ). Pairwise differences are statistically significant only at 5 and $10 \mathrm{mU}\left({ }^{*}\right.$ in $\left.A ; p<0.05\right)$. In addition, somite number is significantly reduced in embryos exposed to $10 \mathrm{mU}$ PIPLC ${ }^{*}$ in $B ; p<$ 0.05), and crown-rump (CR) length is significantly reduced in embryos exposed to 5 and $10 \mathrm{mU}$ PIPLC ${ }^{*}$ in $\left.C ; p<0.05\right)$. (D-G) Effect of treatment with EphA3-AP and EphA1-FC fusion proteins on PNP length (D), PNP width (E), somite number $(\mathbf{F})$ and crown-rump length $(\mathbf{G})$. Compared with $A P$ and $F_{C}$ controls, both EphA3-AP and EphA1-FC significantly increase PNP length (D: $\left.{ }^{*}, p<0.005 ;{ }^{*} * *, p<0.001\right)$ and width $\left(E:{ }^{*}, p<0.05\right.$; $* * *, p<0.001)$, whereas there is no effect on somite number or crownrump length $(F, G)$. Values are mean \pm SEM. Sample sizes: (i) PIPLC experiments: $0.5 \mathrm{mU}, 6$ PIPLC/7 FG; $1.0 \mathrm{mU}, 6$ PIPLC/5 FG; $5.0 \mathrm{mU}, 45$ PIPLC/31 FG; $10.0 \mathrm{mU}, 6$ PIPLC/6 FG; (ii) EphA fusion protein experiments: 19 EphA3-AP/20 AP; 22 EphA1-Fc/15 Fc. Fusion protein concentrations: EphA3-AP, 15 nM; EphA1-Fc, 13 nM. In preliminary studies, these concentrations were the maximum compatible with normal development in culture.

not have a direct linkage to the cytoplasm, signaling is thought to be mediated by tyrosine kinases that are associated with lipid rafts containing ephrinAs (Murai and Pasquale, 2003).

In our intra-amniotic perturbation experiments, we used EphA1Fc and EphA3-AP fusion proteins which bind endogenous ephrinA ligands, blocking their physical interaction with endogenous EphAs and thereby inhibiting forward signalling via the EphA tyrosine kinases (Ciossek et al., 1998). This treatment was able to significantly delay the progression of PNP closure, suggesting a role for either EphA-ephrinA physical interaction or forward signaling, or both, in neural tube closure. Further studies will be needed to distinguish between these two possible functions of EphA-ephrinA interactions in spinal neurulation. Since soluble EphA-Fc and EphA-AP fusion proteins adopt a dimeric conformation (Ciossek et al., 1998), they could have generated reverse signalling in these studies, via their binding to endogenous GPI-anchored ephrinAs. Since PNP closure was delayed, we conclude that reverse ephrinA signalling is unlikely to be necessary for spinal neural tube closure. A further possibility, that excessive reverse ephrinA signalling is induced and that this contributes to the PNP closure delay, cannot be discounted at present.

\section{EphA-ephrinA interactions and development of cellular pro- cesses at the fusion site}

Neural fold fusion involves the formation of lamellipodial processes at the neural fold tips immediately prior to the initial contact (Waterman, 1975; Waterman, 1976; Rice and Moran, 1977; Geelen and Langman, 1979; Lawson and England, 1998). Our electron microscopic observations of mouse spinal neurulation confirm this finding and raise the question as to whether EphA-ephrinA interactions may be involved in regulating this cellular behaviour. The small GTPase Rac is known to induce membrane ruffling and lamellipodia formation both in cultured fibroblasts (Nobes and Hall, 1999) and in morphogenetic events such as dorsal closure in Drosophila (Woolner et al., 2005). Inhibition of Rac function suppresses lamellipodia formation, while Rac overexpression causes excessive numbers of protrusions. In tumour cells, EphA2 is known to promote cell motility (Fang et al., 2005) whereas EphA2deficient cells fail to activate Rac upon stimulation with ephrinA1 (Brantley-Sieders et al., 2004). Hence, there may be a direct correlation between expression of EphA2 on the neural folds tips and occurrence of lamellipodial protrusions.

The situation is likely to be more complex than this, however. In kidney epithelial cells, hepatocyte growth factor-induced branching morphogenesis is associated with cellular protrusion, and yet stimulation of EphA receptors by ephrinA ligands causes the withdrawal of cellular processes from morphogenetically active epithelia, with suppression of Rac1 (Miao et al., 2003). It appears that stimulation of EphA2 by ephrinA1, at least in tumour cells, leads to enhanced turnover of EphA2 from the cell surface and reduced migratory activity. Shp2, a cytoplasmic tyrosine phosphatase and tumour suppressor protein, is recruited to sites of EphA2-ephrinA1 interaction (Miao et al., 2000), leading to disassembly of EphA2 from an active complex with focal adhesion kinase. Interestingly, spina bifida has been reported in mice null for Shp2 (Saxton and Pawson, 1999), raising the possibility that ligand-dependent suppression of forward signaling via EphA2 might be of functional importance in neural tube closure. Clearly, further studies are required to fully determine the role of EphAephrinA interactions in the regulation of lamellipodial protrusions during adhesion and fusion of the neural tube.

\section{Functional redundancy in EphA-ephrinA interactions during neurulation}

EphA2 shows a particularly strong temporal and spatial correlation with neural fold fusion in the mouse PNP. A gene targeted 
knockout of EphA2 (Brantley-Sieders et al., 2004) and three EphA2 gene-trap mutant lines (Mitchell et al., 2001; NaruseNakajima et al., 2001; Chen et al., 1996) have been described, but in no case were neurulation defects observed. The EphA2 knockout displays impaired ephrinA1-induced angiogenesis in vivo, while homozygotes for one of the EphA2 gene trap mutants are described as having short, kinked tails (NaruseNakajima et al., 2001). Hence, there is currently no evidence that loss of EphA2 function alone leads to failure of spinal neurulation. Similarly, of the several EphA4 mutants described, hind limb and gait defects are observed, but no overt neural tube defects (Coulthard et al., 2002). EphA1, and A5 were also found to be expressed in the closing PNP, but no mutants for these genes have yet been described. It seems possible, therefore, that EphA receptors exhibit functional redundancy during spinal neurulation.

The situation is less conclusive for the ephrinAs. While the ephrinA3 knockout mouse displays only defects of the olfactory system (Cutforth et al., 2003), there are currently no described knockouts or gene-trap mutants for ephrinA1 or A4, both of which were expressed in the closing PNP. It remains to be determined whether a single ephrinA might prove to be absolutely required for spinal neural tube closure, or whether functional redundancy will be the case here, as well as for the EphAs.

In conclusion, this paper has demonstrated a requirement for ephrinA-EphA interactions in closure of the mouse spinal neural tube. We also present circumstantial evidence to support the idea that ephrinA-EphA interactions may participate in the molecular recognition events that culminate in adhesion and fusion of the tips of the neural folds.

\section{Materials and Methods}

\section{In situ hybridisation and RT-PCR}

Whole-mount in situ hybridisation, followed by preparation of either $10 \mu \mathrm{m}$ paraffin sections or $50 \mu \mathrm{m}$ vibratome sections, was performed using digoxygenin-labelled cRNA probes (Copp et al., 1999). Previously published probes were used for ephrinA1, A2, A3 and A5, and for EphA2 and A4 (Gale et al., 1996; Flenniken et al., 1996). New cDNA probes were prepared by RT-PCR on total RNA extracted using TRIzol reagent (Invitrogen, UK) from E8.5 and E9.5 CD1 embryos. Amplified fragments were cloned into the pGEM-T vector (Promega, UK) and sequenced to confirm identity. Primer sequences were: EphA1: forward 5'CAAGATTGCAAGACTGTGGC 3' and reverse 5'CCTCCCACATTACAATCCCA 3', amplifying a 514 bp fragment (nucleotides 2004 to 2517; GenBank NM_023580); EphA5: forward 5' GGAGAACGGCTCCTTAGACA 3'and reverse 5' GAGCCACAGCGTCCATTGAA 3', amplifying a 728 bp fragment (nucleotides 2662 to 3389; GenBank NM_007937). Additional primer sequences for RT-PCR are available upon request.

\section{Immuno-electron microscopy}

Deciduas containing embryos were quickly dissected from the uterus in DMEM containing $10 \% \mathrm{FBS}$, then transferred into cold fixative ( $0.01 \%$ glutaraldehyde, $2 \%$ PFA, $0.1 \mathrm{M}$ sucrose in $0.05 \mathrm{M}$ sodium cacodylate, $5 \mathrm{mM}$ calcium chloride buffer, $\mathrm{pH}$ 7.4) and dissected further until all extra-embryonic tissues had been removed. Embryos were rinsed in fixative and kept overnight in the same solution. While on ice, embryos were washed for $3 \mathrm{~h}$ in $0.01 \%$ Triton- 100 buffered PBS, and then incubated overnight at $4^{\circ} \mathrm{C}$ in primary rabbit anti-EphA2 antibody (Zymed Invitrogen, UK) diluted 1:500 in 10\% normal goat serum in
PBS. After washing, embryos were incubated overnight at $4^{\circ} \mathrm{C}$ in horseradish peroxidase-conjugated goat anti-rabbit IgG, diluted 1:100 in $0.01 \%$ Triton-100 buffered PBS, before detection with diaminobenzidine solution (Vectastain, Vector Labs, UK). Embryos were then rinsed twice for 5 minutes in $0.05 \mathrm{M}$ sodium cacodylate, transferred to $1 \%$ osmium tetroxide buffered in $0.1 \mathrm{M}$ sodium cacodylate for $2 \mathrm{~h}$, washed in $0.5 \%$ aqueous uranyl acetate for 30 minutes at $4^{\circ} \mathrm{C}$, and then washed twice for 5 minutes each with distilled water. Embryos were dehydrated through an ethanol series, followed by 3 changes of propylene oxide, then resin/propylene oxide at 3 different ratios (1:2; $1: 1 ; 2: 1$ ) for 30 minutes each, before embedding in epoxy resin (Agar 100). Ultra-thin sections were cut on a RMC MT6000 ultramicrotome, using a Diatome diamond knife. Sections were collected on 300 mesh copper grids, then stained briefly in $0.01 \mathrm{M}$ lead citrate and examined using a JEOL 1010 electron microscope. Semi-thin sections cut for light microscopy were stained with $1 \%$ toluidine blue/ $1 \%$ borax.

\section{Receptor Affinity Probe (RAP) assay}

To detect endogenous ephrinA ligands, EphA3-AP fusion protein was used in a RAP assay (Haj et al., 1999). Embryos were dissected free of extra-embryonic membranes in ice-cold Hank's Balanced Salt Solution (HBSS) and dehydrated to $100 \%$ methanol. After re-hydration, embryos were washed in buffer 3 (HBSS containing $20 \mathrm{mM}$ HEPES pH $7.0,0.5 \mathrm{mg} / \mathrm{ml} \mathrm{BSA}$ ), then incubated overnight in $30 \mathrm{nM}$ EphA3-AP fusion protein at $4^{\circ} \mathrm{C}$. After extensive washing in buffer 3 , embryos were fixed in 4\% PFA for 3 minutes, followed by washing in buffer 4 (HBSS containing $20 \mathrm{mM}$ HEPES pH 7.0, $150 \mathrm{mM} \mathrm{NaCl}$ ). After incubation at $65^{\circ} \mathrm{C}$ to inactivate endogenous alkaline phosphatase, embryos were stained for alkaline phosphatase activity using NBT/BCIP. Embryos were then incubated in $20 \%$ gelatine at $65^{\circ} \mathrm{C}$ for $30 \mathrm{~min}$, embedded, and soaked in $4 \%$ PFA for $3-5$ days at $4^{\circ} \mathrm{C}$. Vibratome sections $(40-50 \mu \mathrm{m})$ were mounted in $80 \%$ glycerol/PBS.

\section{Embryo microinjection and culture}

Non-mutant random-bred CD1 mice (Charles River, UK) were paired overnight and females were checked for copulation plugs the following morning, designated embryonic day (E) 0.5. Embryos were explanted at E8.5 and those with 6-8 somites were selected for culture in rat serum (Cockroft, 1990). Embryos were allocated randomly to treatment groups to minimise the effect of litter-litter variations. Phosphatidylinositol-specific PIPLC (P5542, Sigma-Aldrich, Poole UK)(Low et al., 1988) and fusion proteins EphA3-AP (gift of Dr Uwe Drescher) and EphA1-Fc (R\&D Systems, Abingdon UK) were injected directly into the amniotic cavity in order to bypass the yolk sac. Fast Green ( $0.5 \%$ solution) served as an easily visualised injection marker, with phosphate buffered saline (PBS) as the diluent for the enzyme or fusion protein. Microinjection was performed using a hand-held glass micropipette, pulled using a model P-87 Flaming/Brown micropipette puller (Sutter Instrument Co., Novato, USA). Needle tips were positioned in the amniotic cavity by traversing the yolk sac and amnion (Hartig and Hunter, III, 1998), with a total injection volume of 1-2 $\mu \mathrm{I}$. Embryos were discarded if most of the injected substance was not retained in the amniotic sac, or if there was significant leakage from the yolk sac. Following $8 \mathrm{~h}$ culture, embryos were examined for presence of yolk sac circulation, as an indicator of viability, and somites were counted as a measure of developmental progression. Crown-rump length was determined as a measure of embryonic growth, and was defined as the maximum linear distance from top of the embryonic brain to base of the spinal region, without altering embryonic curvature. Length and width of the posterior neuropore were measured as described previously (Copp, 1985). Statistical analysis was by Student's t-test, computed using SigmaStat v.2 (SPSS Inc.).

\section{Acknowledgements}

We thank Dr David Wilkinson and Dr Uwe Drescher for advice and 
reagents during the course of this study. This research was supported by a PhD scholarship from the University of Malaya (to NMAA) and by Wellcome Trust grant 068883 (to AJC and NDEG).

\section{References}

ANDREWS, N.W., ROBBINS, E.S., LEY, V., HONG, K.S. and NUSSENZWEIG, V. (1988). Developmentally regulated, phospholipase C-mediated release of the major surface glycoprotein of amastigotes of Trypanosoma cruzi. J. Exp. Med. 167: 300-314.

BRANTLEY-SIEDERS, D.M., CAUGHRON, J., HICKS, D., POZZI, A., RUIZ, J.C. and CHEN, J. (2004). EphA2 receptor tyrosine kinase regulates endothelial cell migration and vascular assembly through phosphoinositide 3-kinase-mediated Rac1 GTPase activation. J. Cell Sci. 117: 2037-2049.

CHEN, J., NACHABAH, A., SCHERER, C., GANJU, P., REITH, A., BRONSON, R. and RULEY, H.E. (1996). Germ-line inactivation of the murine Eck receptor tyrosine kinase by gene trap retroviral insertion. Oncogene 12: 979-988.

CIOSSEK, T., MONSCHAU, B., KREMOSER, C., LOSCHINGER, J., LANG, S., MULLER, B.K., BONHOEFFER, F. and DRESCHER, U. (1998). Eph receptorligand interactions are necessary for guidance of retinal ganglion cell axons in vitro. Eur. J Neurosci. 10: 1574-1580.

COCKROFT, D.L. (1990). Dissection and culture of postimplantation embryos. In Postimplantation Mammalian Embryos: A Practical Approach (Eds. Copp, A. J. and Cockroft, D. L.). IRL Press, Oxford, pp. 15-40.

COLAS, J.F. and SCHOENWOLF, G.C. (2001). Towards a cellular and molecular understanding of neurulation. Dev. Dyn. 221: 117-145.

COPP, A., COGRAM, P., FLEMING, A., GERRELLI, D., HENDERSON, D., HYNES, A., KOLATSI-JOANNOU, M., MURDOCH, J., and YBOT-GONZALEZ, P. (1999). Neurulation and neural tube closure defects. In Developmental Biology Protocols, Volume 1 (Eds. Tuan, R. S. and Lo, C. W.). Humana Press Inc, Totowa, New Jersey, pp. 135-160.

COPP, A.J. (1985). Relationship between timing of posterior neuropore closure and development of spinal neural tube defects in mutant (curly tail) and normal mouse embryos in culture. J. Embryol. Exp. Morphol. 88: 39-54.

COPP, A.J., GREENE, N.D.E. and MURDOCH, J.N. (2003). The genetic basis of mammalian neurulation. Nat. Rev. Genet. 4: 784-793.

COULTHARD, M.G., DUFFY, S., DOWN, M., EVANS, B., POWER, M., SMITH, F., STYLIANOU, C., KLEIKAMP, S., OATES, A., LACKMANN, M., BURNS, G.F. and BOYD, A.W. (2002). The role of the Eph-ephrin signalling system in the regulation of developmental patterning. Int. J Dev. Biol 46: 375-384.

COULTHARD, M.G., LICKLITER, J.D., SUBANESAN, N., CHEN, K., WEBB, G.C., LOWRY, A.J., KOBLAR, S., BOTTEMA, C.D. and BOYD, A.W. (2001). Characterization of the Epha1 receptor tyrosine kinase: expression in epithelial tissues. Growth Factors 18: 303-317.

CUTFORTH, T., MORING, L., MENDELSOHN, M., NEMES, A., SHAH, N.M., KIM, M.M., FRISEN, J. and AXEL, R. (2003). Axonal ephrin-As and odorant receptors: coordinate determination of the olfactory sensory map. Cell 114: 311-322.

DAVIS, S., GALE, N.W., ALDRICH, T.H., MAISONPIERRE, P.C., LHOTAK, V., PAWSON, T., GOLDFARB, M. and YANCOPOULOS, G.D. (1994). Ligands for $\mathrm{EPH}$-related receptor tyrosine kinases that require membrane attachment or clustering for activity. Science 266: 816-819.

DRAVIS, C., YOKOYAMA, N., CHUMLEY, M.J., COWAN, C.A., SILVANY, R.E., SHAY, J., BAKER, L.A. and HENKEMEYER, M. (2004). Bidirectional signaling mediated by ephrin-B2 and EphB2 controls urorectal development. Dev. Biol. 271: $272-290$.

DRESCHER, U. (1997). The Eph family in the patterning of neural development. Curr. Biol. 7: R799-R807.

FANG, W.B., BRANTLEY-SIEDERS, D.M., PARKER, M.A., REITH, A.D. and CHEN, J. (2005). A kinase-dependent role for EphA2 receptor in promoting tumor growth and metastasis. Oncogene 24: 7859-7868.

FLENNIKEN, A.M., GALE, N.W., YANCOPOULOS, G.D. and WILKINSON, D.G. (1996). Distinct and overlapping expression patterns of ligands for Eph-related receptor tyrosine kinases during mouse embryogenesis. Dev. Biol. 179: 382401.

GALE, N.W., HOLLAND, S.J., VALENZUELA, D.M., FLENNIKEN, A., PAN, L.,
RYAN, T.E., HENKEMEYER, M., STREBHARDT, K., HIRAI, H., WILKINSON, D.G., PAWSON, T., DAVIS, S. and YANCOPOULOS, G.D. (1996). Eph receptors and ligands comprise two major specificity subclasses and are reciprocally compartmentalized during embryogenesis. Neuron 17: 9-19.

GATO, A., MARTINEZ, M.L., TUDELA, C., ALONSO, I., MORO, J.A., FORMOSO, M.A., FERGUSON, M.W.J. and MARTINEZ-ALVAREZ, C. (2002). TGF-b3induced chondroitin sulphate proteoglycan mediates palatal shelf adhesion. Dev. Biol. 250: 393-405.

GEELEN, J.A.G. and LANGMAN, J. (1979). Ultrastructural observations on closure of the neural tube in the mouse. Anat. Embryol. 156: 73-88.

GEORGE, S.E., SIMOKAT, K., HARDIN, J. and CHISHOLM, A.D. (1998). The VAB1 Eph receptor tyrosine kinase functions in neural and epithelial morphogenesis in C. elegans. Cell 92: 633-643.

HAJ, F., MCKINNELL, I. and STOKER, A. (1999). Retinotectal ligands for the receptor tyrosine phosphatase CRYPalpha. Mol. Cell Neurosci. 14: 225-240.

HARTIG, P.C. and HUNTER, E.S., III (1998). Gene delivery to the neurulating embryo during culture. Teratology. 58: 103-112.

HOLMBERG, J., CLARKE, D.L. and FRISÉN, J. (2000). Regulation of repulsion versus adhesion by different splice forms of an Eph receptor. Nature 408: 203206.

HORNBERGER, M.R., DUTTING, D., CIOSSEK, T., YAMADA, T., HANDWERKER, C., LANG, S., WETH, F., HUF, J., WESSEL, R., LOGAN, C., TANAKA, H. and DRESCHER, U. (1999). Modulation of EphA receptor function by coexpressed ephrinA ligands on retinal ganglion cell axons. Neuron 22: 731-742.

LAWSON, A. and ENGLAND, M.A. (1998). Neural fold fusion in the cranial region of the chick embryo. Dev. Dyn. 212: 473-481.

LOW, M.G., STIERNBERG, J., WANECK, G.L., FLAVELL, R.A. and KINCADE, P.W. (1988). Cell-specific heterogeneity in sensitivity of phosphatidylinositolanchored membrane antigens to release by phospholipase C. J Immunol. Methods 113: 101-111.

MERRILL, A.E., BOCHUKOVA, E.G., BRUGGER, S.M., ISHII, M., PILZ, D.T., WALL, S.A., LYONS, K.M., WILKIE, A.O. and MAXSON, R.E., JR. (2006). Cell mixing at a neural crest-mesoderm boundary and deficient ephrin-Eph signaling in the pathogenesis of craniosynostosis. Hum. Mol. Genet. 15: 1319-1328.

MIAO, H., BURNETT, E., KINCH, M., SIMON, E. and WANG, B. (2000). Activation of EphA2 kinase suppresses integrin function and causes focal-adhesionkinase dephosphorylation. Nat Cell Biol 2: 62-69.

MIAO, H., NICKEL, C.H., CANTLEY, L.G., BRUGGEMAN, L.A., BENNARDO, L.N and WANG, B. (2003). EphA kinase activation regulates HGF-induced epithelial branching morphogenesis. J. Cell Biol. 162: 1281-1292.

MITCHELL, K.J., PINSON, K.I., KELLY, O.G., BRENNAN, J., ZUPICICH, L., SCHERZ, P., LEIGHTON, P.A., GOODRICH, L.V., LU, X.W., AVERY, B.J., TATE, P., DILL, K., PANGILINAN, E., WAKENIGHT, P., TESSIER-LAVIGNE, M. and SKARNES, W.C. (2001). Functional analysis of secreted and transmembrane proteins critical to mouse development. Nature Genet. 28: 241-249.

MURAI, K.K. and PASQUALE, E.B. (2003). 'Eph'ective signaling: forward, reverse and crosstalk. J. Cell Sci. 116: 2823-2832.

NARUSE-NAKAJIMA, C., ASANO, M. and IWAKURA, Y. (2001). Involvement of EphA2 in the formation of the tail notochord via interaction with ephrinA1. Mech. Dev. 102: 95-105.

NOBES, C.D. and HALL, A. (1999). Rho GTPases control polarity, protrusion, and adhesion during cell movement. J. Cell Biol. 144: 1235-1244.

O'SHEA, K.S. and KAUFMAN, M.H. (1980). Phospholipase C induced neural tube defects in the mouse embryo. Experientia 36: 1217-1219.

PASQUALE, E.B. (2005). EPH receptor signalling casts a wide net on cell behaviour. Nat. Rev. Mol. Cell Biol. 6: 462-475.

RICE, R.W. and MORAN, D.J. (1977). A scanning electron microscopic and x-ray microanalytic study of cell surface material during amphibian neurulation. $J$. Exp. Zool. 201: 471-478.

SADLER, T.W. (1978). Distribution of surface coat material on fusing neural folds of mouse embryos during neurulation. Anat. Rec. 191: 345-350.

SAXTON, T.M. and PAWSON, T. (1999). Morphogenetic movements at gastrulation require the SH2 tyrosine phosphatase Shp2. Proc. Natl. Acad. Sci. USA 96: 3790-3795.

SCHOENWOLF, G.C. and SMITH, J.L. (1990). Mechanisms of neurulation: Tradi- 
tional viewpoint and recent advances. Development 109: 243-270.

SMITS VAN PROOIJE, A.E., POELMANN, R.E., GESINK, A.F., VAN GROENINGEN, M.J. and VERMEIJ KEERS, C. (1986). The cell surface coat in neurulating mouse and rat embryos, studied with lectins. Anat. Embryol. 175: 111-117.

STEPHEN, L.J., FAWKES, A.L., VERHOEVE, A., LEMKE, G. and BROWN, A. (2007). A critical role for the EphA3 receptor tyrosine kinase in heart development. Dev. Biol. 302: 66-79.

TAO, H., SHIMIZU, M., KUSUMOTO, R., ONO, K., NOJI, S. and OHUCHI, H. (2005). A dual role of FGF10 in proliferation and coordinated migration of epithelial leading edge cells during mouse eyelid development. Development 132: 3217-3230.

WATERMAN, R.E. (1975). SEM observations of surface alterations associated with neural tube closure in the mouse and hamster. Anat. Rec. 183: 95-98.

WATERMAN, R.E. (1976). Topographical changes along the neural fold associated with neurulation in the hamster and mouse. Am. J. Anat. 146: 151-171.

WOOLNER, S., JACINTO, A. and MARTIN, P. (2005). The small GTPase Rac plays multiple roles in epithelial sheet fusion - Dynamic studies of Drosophila dorsal closure. Dev. Biol. 282: 163-173.

\section{Further Related Reading, published previously in the Int. J. Dev. Biol.}

See our recent Special Issue Fertilization, in honor of David L. Garbers and edited by Paul M. Wassarman and Victor D. Vacquier at: http://www.ijdb.ehu.es/web/contents.php?vol=52\&issue=5-6

Common mechanisms for boundary formation in somitogenesis and brain development: shaping the 'chic' chick

Yoshiko Takahashi

Int. J. Dev. Biol. (2005) 49: 221-230

The role of the Eph-ephrin signalling system in the regulation of developmental patterning.

Mark G Coulthard, Shannon Duffy, Michelle Down, Betty Evans, Maryanne Power, Fiona Smith, Con Stylianou, Sabine Kleikamp, Andrew Oates, Martin Lackmann, Gordon F Burns and Andrew W Boyd

Int. J. Dev. Biol. (2002) 46: 375-384

Neurulation in amniote vertebrates: a novel view deduced from the use of quail-chick chimeras.

N M Le Douarin, M A Teillet and M Catala

Int. J. Dev. Biol. (1998) 42: 909-916

Genetic patterning of the posterior neuropore region of curly tail mouse embryos: deficiency of Wnt5a expression.

F Gofflot, M Hall and G M Morriss-Kay

Int. J. Dev. Biol. (1998) 42: 637-644

Mechanisms of normal and abnormal neurulation: evidence from embryo culture studies.

A Fleming, D Gerrelli, N D Greene and A J Copp

Int. J. Dev. Biol. (1997) 41: 199-212

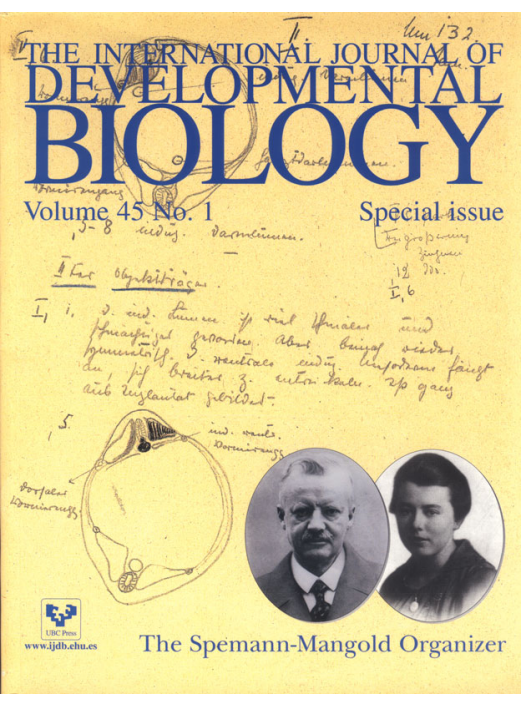

2006 ISI **Impact Factor $=3.577^{* *}$

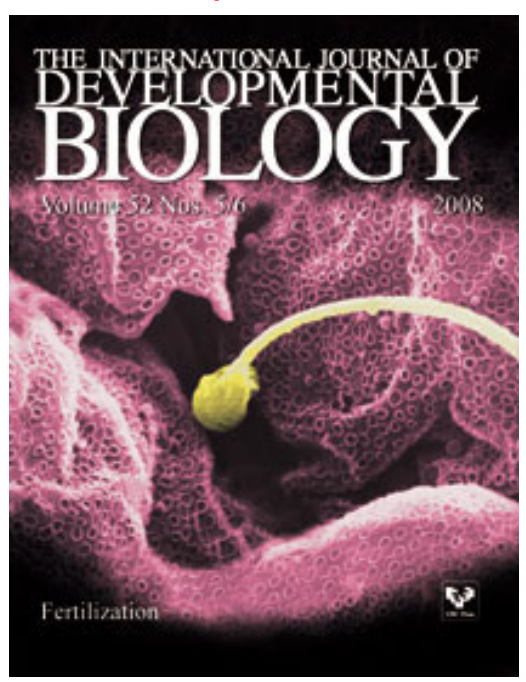

